\title{
The Development of High Field Magnets Utilizing Bi-2212 Wind \& React Insert Coils
}

\author{
Chris M. Friend, Hanping Miao, Yibing Huang, Ziad Melhem, Fred Domptail, Maarten Meinesz, Seung Hong, \\ Edward A. Young, and Yifeng Yang
}

\begin{abstract}
Wind \& react $B \mathbf{i}-2212$ inserts have been manufactured and tested inside a wide-bore $\mathrm{NbTi}-\mathrm{Nb}_{3} \mathrm{Sn}$ magnet providing a background field up to $20 \mathrm{~T}$ at $4.2 \mathrm{~K}$. A pair of six-layer concentric coils both achieved critical currents of 350 A $\left(J_{E}=200 \mathrm{~A} / \mathrm{mm}^{2}\right)$ in a $20 \mathrm{~T}$ background field. A thicker 14-layer insert made from $119 \mathrm{~m}$ of round wire had a critical quench current $I_{Q}$ of $287 \mathrm{~A}\left(J_{E}=162 \mathrm{~A} / \mathrm{mm}^{2}\right)$ at the same field and contributed to a combined central field of $22.5 \mathrm{~T}$. This is a record for a fully superconducting magnet at $4.2 \mathrm{~K}$. The 14-layer coil, equipped with an external protective shunt, was used for an extensive series of quench measurements and endured $>150$ quenches without damage. Minimum quench energies were found to be in the range of $200-500 \mathrm{~mJ}$ in background fields of 15-20 $\mathrm{T}$ when the coil carried 70-95\% of its critical quench current.
\end{abstract}

Index Terms-Bi-2212, high field magnet, high temperature superconductor, quench.

\section{INTRODUCTION}

$\mathbf{T}$ HE last three years has witnessed a marked improvement in the performance of long length $\mathrm{Bi}_{2} \mathrm{Sr}_{2} \mathrm{CaCu}_{2} \mathrm{O}_{8-\mathrm{x}}$ (Bi-2212) round wires and wind \& react coils made with them. In 2008, a combined field of $32.1 \mathrm{~T}$ was achieved with a Bi-2212 coil inside a $31 \mathrm{~T}$ resistive magnet [1].

This paper demonstrates the current state-of-the-art for Bi-2212 insert coils and how close the technology is to providing wide availability of fully superconducting systems at 25 $\mathrm{T}$ and above.

The work was undertaken as part of a UK collaborative project with the acronym "IMPDAHMA" by Oxford Instruments Nanoscience, Cobham Technical Services Vector Fields Software and Southampton University. The aim of this project is to develop a software design module (as an optional addition to OPERA) for modeling the thermal and electromagnetic behavior of high temperature superconductor (HTS) coils in applications. To obtain data on the quench behavior of HTS coils and to verify models, a series of HTS insert coils were

Manuscript received October 19, 2009. First published April 05, 2010; current version published May 28, 2010. This work was supported in part by the Technology Strategy Board of the UK (Grant TP/5/MAT/6/I/H0647BT).

C. M. Friend, Z. Melhem, and F. Domptail are with Oxford Instruments Nanoscience, Tubney Woods, Abingdon, Oxon OX13 5QX, U.K. (e-mail: chris.friend@physics.org).

H. Miao, Y. Huang, M. Meinesz, and S. Hong are with Oxford Superconducting Technology, Carteret, NJ 07008-0429, USA.

E. A. Young and Y. Yang are with The Institute of Cryogenics, University of Southampton, Southampton SO17 1BJ, U.K.

Color versions of one or more of the figures in this paper are available online at http://ieeexplore.ieee.org.

Digital Object Identifier 10.1109/TASC.2010.2043237

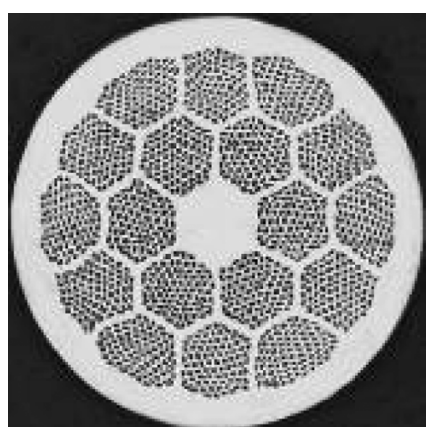

Fig. 1. A cross-section of the $85 \times 19 \mathrm{Bi}-2212 / \mathrm{Ag}$ wire manufactured by OST and used in the insert coils of the IMPDAHMA project.

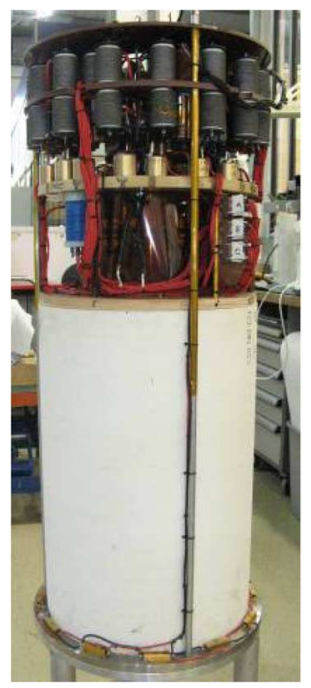

Fig. 2. Photo of the Oxford Instruments $20 \mathrm{~T} / 78 \mathrm{~mm}$ bore LTS magnet outside its cryostat.

tested in a new high-field/wide-bore low temperature superconducting (LTS) magnet that provides $20 \mathrm{~T}$ in a $78 \mathrm{~mm}$ bore at 4.2 $\mathrm{K}$. Though the design package will cover all HTS conductors, in this phase, the high field testing and verification has focused on $\mathrm{Bi}-2212$ round wire inserts.

In the future, integrated LTS-HTS high field magnets providing $25 \mathrm{~T}$ at $4.2 \mathrm{~K}$ will be attractive alternatives to large, costly, resistive systems.

\section{Development of Bi-2212 WiRES AND CoILS}

The best long length $\mathrm{Bi}-2212$ round wires manufactured by Oxford Superconducting Technology (OST) have an $85 \times 19$ filament geometry. Fig. 1 shows a cross-section of this wire. The innermost restack element is substituted by a silver rod. The highest $J_{E}$ of $320 \mathrm{~A} / \mathrm{mm}^{2}$ at $25 \mathrm{~T}$ and $4.2 \mathrm{~K}$ was obtained in 


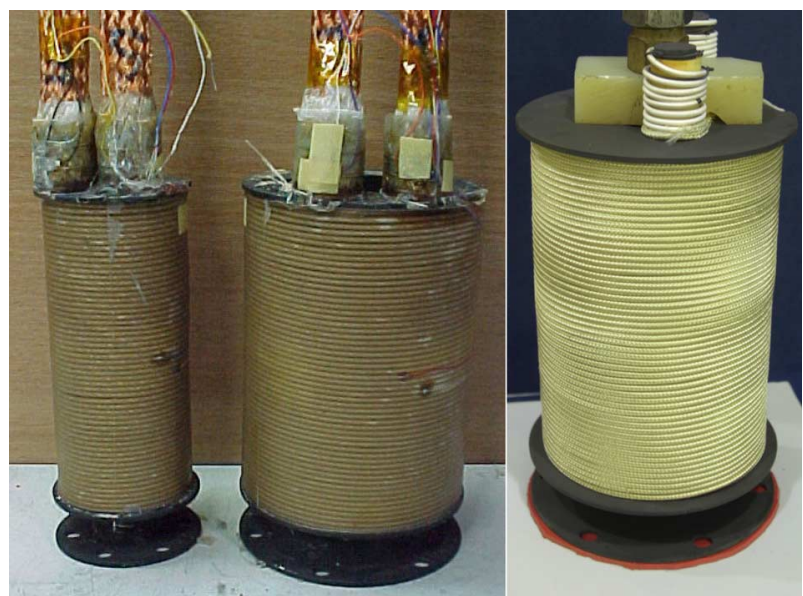

Fig. 3. Photos of (left) the inner and outer coaxial inserts after being instrumented and vacuum impregnated with resin and (right) the thick insert coil after heat treatment but before potting.

TABLE I

Bi-2212 INSERT SPECIFICATIONS

\begin{tabular}{cccc}
\hline \hline Parameter / Coil & $\begin{array}{c}\text { Coax- } \\
\text { Inner }\end{array}$ & $\begin{array}{c}\text { Coax- } \\
\text { outer }\end{array}$ & $\begin{array}{c}\text { Thick } \\
\text { insert }\end{array}$ \\
\hline $\begin{array}{c}\text { Inner winding diameter } \\
\text { (mm) }\end{array}$ & 25.5 & 55.5 & 25.5 \\
$\begin{array}{c}\text { Outer winding diameter } \\
(\mathrm{mm})\end{array}$ & 44.6 & 74.2 & 70 \\
$\begin{array}{c}\text { Winding Height (mm) } \\
\text { Wire length (m) }\end{array}$ & 100 & 100 & 100 \\
Number of turns & 38.5 & 69.4 & 119 \\
Number of layers & 6 & 333 & 770 \\
Turns density (turns $\left./ \mathrm{cm}^{2}\right)$ & 35 & 635 & 14 \\
\hline \hline
\end{tabular}

the $1.15 \mathrm{~mm}$ diameter wire [2]. Because of the larger thermal mass and interactions with former/insulation it has been difficult to replicate this level of performance in wind \& react coils [3], [4], however, during this project, improved handling and heat treatment processes [5] by OST has significantly narrowed this performance gap.

All the inserts described in this paper were made from $1.5 \mathrm{~mm}$ diameter wire, braided with $\mathrm{Al}_{2} \mathrm{O}_{3}-\mathrm{SiO}_{2}$ insulation, wound onto an inconel former and then heat treated.

\section{THE 20 TESLA Wide Bore LTS MAGNET}

A wide-bore $\mathrm{NbTi}-\mathrm{Nb}_{3} \mathrm{Sn}$ magnet was commissioned as a test-bed system for the IMPDAHMA project to test the HTS insert coils. This compact high field magnet has a cold bore of $78 \mathrm{~mm}$, an outer diameter of $41 \mathrm{~cm}$ and a height of $61 \mathrm{~cm}$. It generates a background field of $20 \mathrm{~T}$ at $4.2 \mathrm{~K}$ with an operating current of 140 Amps. This is currently a record field for an LTS magnet at $4.2 \mathrm{~K}$ with a wide bore and builds upon technology developed for compact high field magnets from internal-tin conductors [6]-[8].

Fig. 2 is a photo of the $20 \mathrm{~T}$ magnet. Two test runs of HTS insert coils at $4.2 \mathrm{~K}$ inside this system are described in the fol-

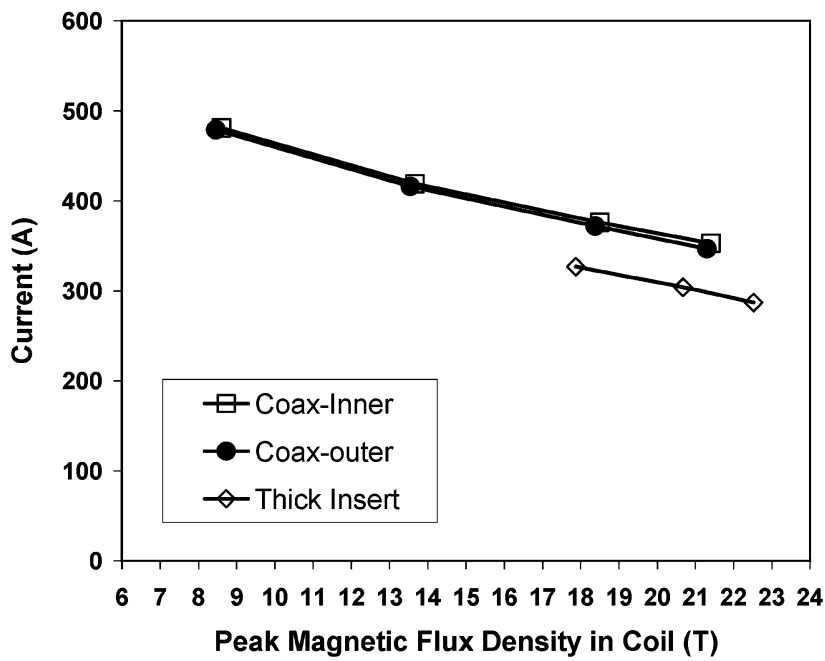

Fig. 4. The critical current $(0.1 \mu \mathrm{V} / \mathrm{cm}$ criterion $)$ at $4.2 \mathrm{~K}$ of the two coaxial inserts coils and the quench current of the thick insert plotted against the peak magnetic flux density generated in the coil. The coaxial coils are powered separately. The background field generated by the LTS outer was $6.7 \mathrm{~T}, 12 \mathrm{~T}, 17 \mathrm{~T}$, and $20 \mathrm{~T}$ for the four data points for each coaxial coil, and $15 \mathrm{~T}, 18 \mathrm{~T}$, and $20 \mathrm{~T}$ for the three data points of the thick insert.

lowing sections. In the first test, two concentric inserts, each of six layers, were tested separately and in series. In the second test a single thicker insert of 14 layers was measured.

\section{CoAXial Insert Coils (22.07 Tesla System)}

Fig. 3 shows the two 6-layer insert coils that were assembled concentrically inside the $20 \mathrm{~T}$ magnet bore. Whilst each coil had $0.5 \Omega$ resistor at $4.2 \mathrm{~K}$ in parallel with it, there was no external protective shunt. The main dimensional parameters are listed in Table I.

The critical current, $I_{C}$, of each coil was measured separately in background fields of $6.7-20 \mathrm{~T}$ at $4.2 \mathrm{~K}$. Fig. 4 plots their $I_{C}$ values versus the peak field generated in the coil at that current. A criterion of $0.1 \mu \mathrm{V} / \mathrm{cm}$ was used to define $I_{C}$. The coils quenched at currents just a little above the critical value. The data show that both coils have similar performance with $I_{C}=350 \mathrm{~A}$ and $J_{E}=200 \mathrm{~A} / \mathrm{mm}^{2}$ at $21 \mathrm{~T}$. The $1 \mathrm{~m}$ witness sample, placed inside the coil bore during heat treatment had the same $I_{C}$. The $n$ values for each coil varied from 22 to 28 .

Unfortunately, during further V-I tests at $20 \mathrm{~T}$, the inner coaxial coil unexpectedly quenched at a current lower than its initial $\mathrm{I}_{\mathrm{C}}$, after which it was found to have degraded with a reduced n-value. The two coils were then energized in series to a current of $280 \mathrm{~A}$ in a background field of $20 \mathrm{~T}$, generating a total central field of $22.07 \mathrm{~T}$ (this corresponds to current density in the winding of $98 \mathrm{~A} / \mathrm{mm}^{2}$ ). Had the inner coil not degraded, we would have expected the pair to produce an additional field that was up to $25 \%$ higher, i.e. $+2.6 \mathrm{~T}$.

Finally, both coils were subjected to tens of forced quenches by applying heat pulses much higher than the minimum quench energies. No further degradation was observed in either coil.

\section{THE 14-LAYER Bi-2212 INSERT COIL}

The third coil tested in the $20 \mathrm{~T}$ system was a single thick insert of 14 layers. Its specifications are given in Table I. This 
TABLE II

MAGNET SPECIFICATIONS

\begin{tabular}{cc}
\hline \hline Parameter & Value \\
\hline Operating temperature $(\mathrm{K})$ & 4.2 \\
\hline Magnetic flux density at centre (Tesla) & 22.5 \\
Component supplied by Bi-2212 insert (T) & 2.5 \\
Variation over 1 cm volume at centre (\%) & $<0.01$ \\
Magnet outer diameter (cm) & 41 \\
Magnet height (cm) & 61 \\
Cold bore diameter (mm) & 23.5 \\
Bi-2212 insert current at max. field (A) & $287 \mathrm{~A}$ \\
LTS current at max. field $(\mathrm{A})$ & $140 \mathrm{~A}$ \\
Bi-2212 insert self inductance $(\mathrm{mH})$ & 7.8 \\
Bi-2212 wire $\mathrm{J}_{\mathrm{E}}$ at 22.5 T, no insulation $\left(\mathrm{A} / \mathrm{mm}^{2}\right)$ & 162 \\
Bi-2212 insert coil $\mathrm{J}_{\mathrm{E}}$ at $22.5 \mathrm{~T}\left(\mathrm{~A} / \mathrm{mm}^{2}\right)$ & 101 \\
\hline \hline
\end{tabular}

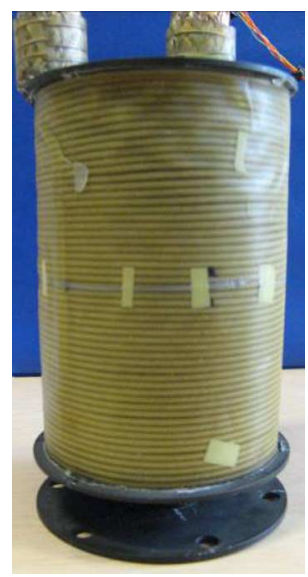

Fig. 5. The thick insert coil after resin impregnation under vacuum showing the constantan ribbon heater that is non-inductively wound around the middle turn of the outer layer.

coil required a modified heat treatment process to cope with the larger thermal mass and to ensure a uniform temperature profile throughout the full winding volume. As with previous coils, no leakage spots were observed on the outer layer. Before potting, a quench heater, consisting of a thin ribbon of constantan, $40 \mu \mathrm{m} \times 1 \mathrm{~mm}$, was wound non-inductively onto the middle turn of the outer layer (it was wound once round the circumference then doubled back on itself with insulation inbetween to complete a second turn). The heater had a resistance of $8 \Omega$ and surface area of $2.1 \mathrm{~cm}^{2}$ in contact with the coil. Fig. 5 shows the heater in place after potting. To prevent the degradation that occurred in one of the previous coils, a protective shunt of $4 \mathrm{~m} \Omega$ resistance was placed across the current terminals of the coil, outside the cryostat.

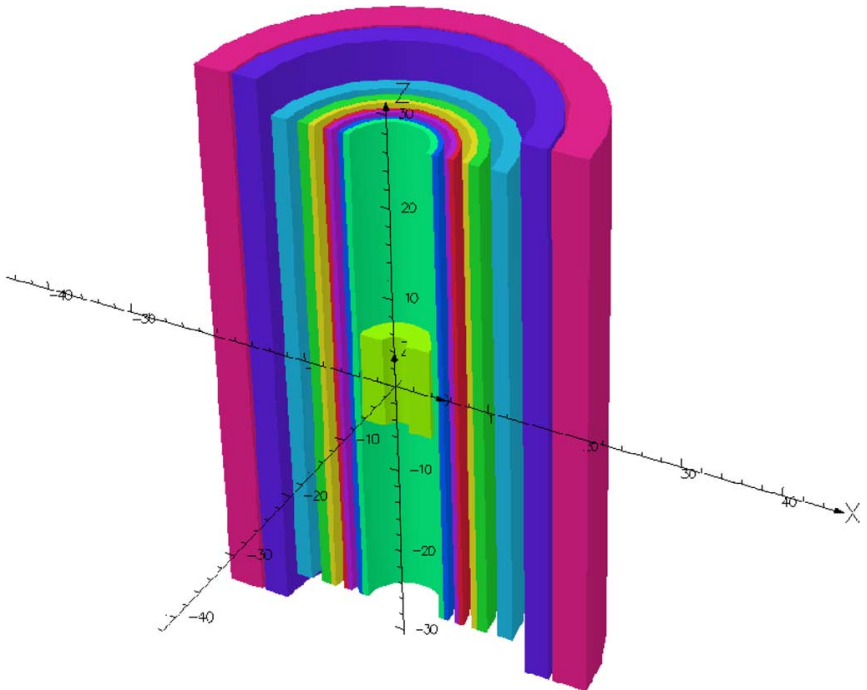

Fig. 6. Schematic of the integrated LTS-HTS 22.5 Tesla Magnet System. The HTS insert is the innermost green coil, the two outermost coils are NbTi and the remainder are $\mathrm{Nb}_{3} \mathrm{Sn}$ coils.

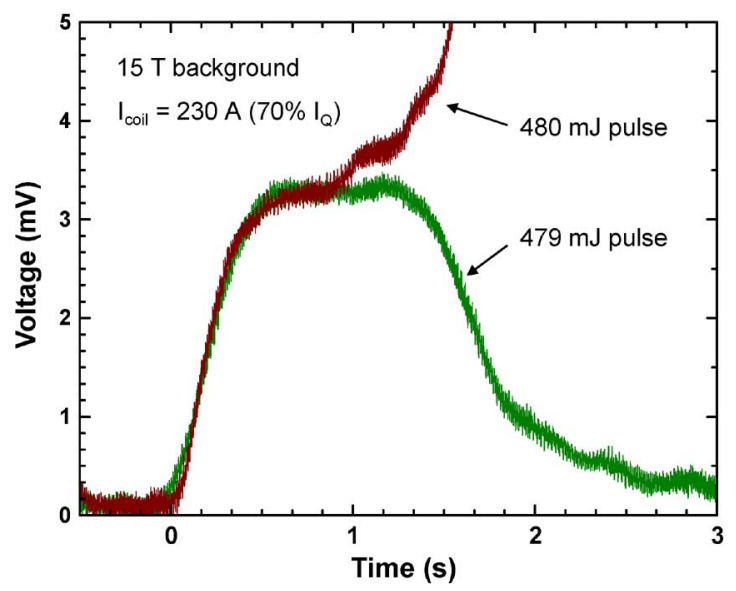

Fig. 7. The resistive voltage of the thick insert coil during heat pulses of $479 \mathrm{~mJ}$ and $480 \mathrm{~mJ}$ applied by the constantan ribbon heater whilst the coil is carrying $230 \mathrm{~A}\left(70 \%\right.$ of $\left.I_{Q}\right)$ in a background field of $15 \mathrm{~T}$. The coil quenches with the $480 \mathrm{~mJ}$ pulse but not at $479 \mathrm{~mJ}$.

\section{The InTEgrated 22.5 Tesla Magnet System}

As with the previous coils, the 14-layer insert was tested inside the 20 T LTS magnet. Fig. 6 is a schematic of this integrated LTS-HTS system. The $V-I$ characteristic of the coil was measured before and after all forced quenches. A critical current could not be measured using the $0.1 \mu \mathrm{V} / \mathrm{cm}$ criterion as the coil always quenched at a voltage level well below this. The measured quench currents, $I_{Q}$, in background fields of 15,18 and $20 \mathrm{~T}$ are plotted in Fig. 4. In a background field of $20 \mathrm{~T}$ the coil had $I_{Q}=287 \mathrm{~A}$, corresponding to an engineering current density of $J_{E}=101 \mathrm{~A} / \mathrm{mm}^{2}$ averaged across the windings, and generated an additional field of $2.5 \mathrm{~T}$ in the central bore. The combined field of $22.5 \mathrm{~T}$ is a record for a fully superconducting magnet system operating at $4.2 \mathrm{~K}$. The key specifications for this high field LTS-HTS system are listed in Table II. 


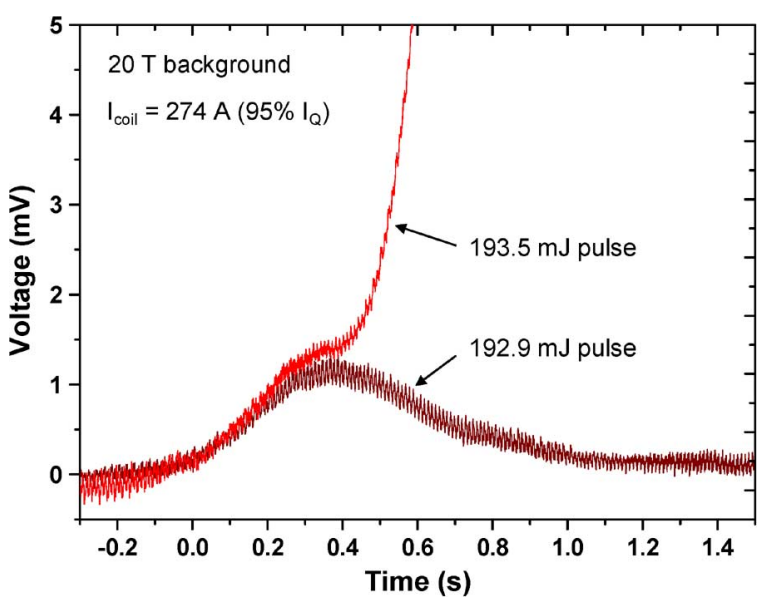

Fig. 8. The resistive voltage of the thick insert coil during heat pulses of 192.9 $\mathrm{mJ}$ and $193.5 \mathrm{~mJ}$ applied by the constantan ribbon heater whilst the coil is carrying $274 \mathrm{~A}\left(95 \%\right.$ of $\left.I_{Q}\right)$ in a background field of $20 \mathrm{~T}$. The coil quenches with the $193.5 \mathrm{~mJ}$ pulse but not at $192.9 \mathrm{~mJ}$.

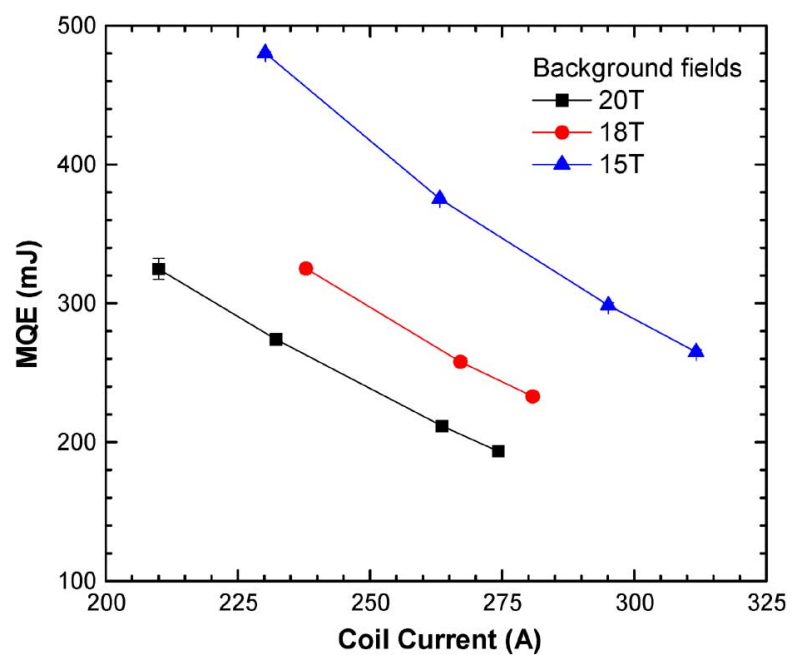

Fig. 9. The minimum quench energies (MQE) of the 14-layer insert coil as a function of the transport current in the Bi-2212 at three different background fields.

\section{Minimum Quench ENERGIES OF A Bi-2212 CoIL}

Resistive voltages - the inductive component of the measured signal having been calculated from the rate of change of current flowing in the coil and subtracted [10]. Fig. 7 plots results in a $15 \mathrm{~T}$ background field when the insert has a current of $230 \mathrm{~A}$ (70\% of $I_{Q}$ at this field). A heater pulse of $479 \mathrm{~mJ}$ causes the coil voltage to rise to just over $3 \mathrm{mV}$, then plateau and eventually reduce back down to zero as the coil cools. However, applying a heater pulse of just $1 \mathrm{~mJ}$ higher causes the coil to quench at $\mathrm{t}=0.9 \mathrm{~s}$. In this case the MQE is $480 \mathrm{~mJ}$.

Fig. 8 shows similar behavior for the coil when carrying a current that is just $5 \%$ lower than $I_{Q}$ at $274 \mathrm{~A}$, in a background field of $20 \mathrm{~T}$. In this situation, a heater pulse of $192.9 \mathrm{~mJ}$ causes the voltage to rise to $1.3 \mathrm{mV}$ before the coil recovers. Injecting just $0.6 \mathrm{~mJ}$ more into the coil causes it to quench after $0.4 \mathrm{sec}-$ onds.
The minimum quench energies at background fields of 15, 18 and $20 \mathrm{~T}$ are plotted against the coil current in Fig. 9.

The MQE decreases as the current gets closer to $I_{Q}$ and as the field $/ I_{Q}$ decreases. These values, of 100's of $\mathrm{mJ}$ are ten to one hundred times larger than those typically found in LTS wires [11]. Overall, counting all $I_{Q}$ and MQE measurements, this insert coil suffered more than 150 quenches without any degradation in its properties.

\section{Future Higher FIELD SySTEMS With Bi-2212}

Fully superconducting magnets with fields of $25 \mathrm{~T}$ or higher should be achievable with $\mathrm{Bi}-2212$ in the near future. The performance of wind \& react coils continues to approach that of short samples and as even the best wires have a $J_{C}$ that is only $5 \%$ of the values found in thin films [12], there is considerable scope to further increase the wire $J_{E}$.

Characterization and modeling of the quench behavior will enable the design of appropriate detection and protection systems for high field LTS-HTS systems.

\section{ACKNOWLEDGMENT}

The authors would like to thank everyone who contributed to this work, including but not limited to: C. Watkins, A. Twin, G. Farmer, P. Ghoshal, R. Harrison, C. Morris, P. Noonan, E. Xu, and J. Parrell.

\section{REFERENCES}

[1] H. W. Weijers, W. D. Markiewicz, K. W. Pickard, P. D. Noyes, U. P. Trociewitz, J. Jiang, and D. C. Larbalestier, Tests of HTS Insert Coils Above $30 \mathrm{~T}$, unpublished.

[2] H. Miao, M. Meinesz, B. Czabaj, J. Parrell, and S. Hong, "Microstructure and Jc improvements in multifilamentary Bi-2212/Ag wires for high field magnet applications," Adv. Cryo. Eng. Mat., vol. 54, pp. 423-430, 2008.

[3] H. Miao, K. R. Marken, M. Meinesz, B. Czabaj, S. Hong, A. Twin, P. Noonan, U. Trociewitz, and J. Schwartz, "High field insert coils from Bi-2212/Ag round wires," IEEE Trans. Appl. Supercond., vol. 17, no. 2, pp. 2262-2265, 2007.

[4] U. P. Trociewitz, Bi-2212 Conductor and Coil Technology for High Field Magnets, to be published.

[5] Patent application pending.

[6] S. Hong, M. B. Field, J. A. Parrell, and Y. Zhang, "Latest improvements of current carrying capability of niobium tin and its magnet applications," IEEE Trans. Appl. Supercond., vol. 16, no. 2, pp. 1146-1151, 2006.

[7] A. Twin, J. Brown, F. Domptail, R. Bateman, R. Harrison, M. Lakrimi, Z. Melhem, P. Noonan, M. Field, S. Hong, K. Marken, H. Miao, J. Parrell, and Y. Zhang, "Present and future applications for advanced superconducting materials in high field magnets," IEEE Trans. Appl. Supercond., vol. 17, no. 2, pp. 2295-2298, 2007.

[8] R. Harrison, R. Bateman, J. Brown, F. Domptail, C. Friend, P. Ghoshal, C. King, A. van der Linden, Z. Melhem, P. Noonan, and A. Twin et al., "Development trends in high field magnet technology," IEEE Trans. Appl. Supercond., vol. 18, no. 2, pp. 540-543, 2008.

[9] E. A. Young, C. M. Friend, and Y. Yang, "Quench characteristics of a stabilizer-free 2G HTS conductor," IEEE Trans. Appl. Supercond., vol. 19, no. 3, pp. 2500-2503, 2009.

[10] C. M. Friend, E. A. Young, and Y. Yang, Measurements of the Quench Dynamics of Bi-2212 Insert Coils in Fields Up to 22.5 Tesla, to be published.

[11] M. N. Wilson, Superconducting Magnets. Oxford, U.K.: Oxford University Press, 1987.

[12] N. T. Mua, C. R. Serrao, Shipra, T. D. Hien, and N. K. Man, "High critical current density in Ag-doped Bi-2212 thin films," Supercond. Sci. Technol., vol. 21, no. 10, p. 105002, 2008, (5pp). 